\title{
Analysis of Agonist and Antagonist Activities of Phenylglycine Derivatives for Different Cloned Metabotropic Glutamate Receptor Subtypes
}

\author{
Yasunori Hayashi, ${ }^{1,2}$ Naohiro Sekiyama, ${ }^{1}$ Shigetada Nakanishi, ${ }^{1}$ David E. Jane, ${ }^{3}$ David C. Sunter, ${ }^{3}$ \\ Ewan F. Birse, ${ }^{3}$ Peter M. Udvarhelyi, ${ }^{3}$ and Jeffrey C. Watkins ${ }^{3}$ \\ 'Institute for Immunology and ${ }^{2}$ Department of Pharmacology, Kyoto University Faculty of Medicine, Kyoto 606, Japan and \\ ${ }^{3}$ Department of Pharmacology, School of Medical Sciences, Bristol BS8 1TD, United Kingdom
}

The metabotropic glutamate receptors (mGluRs) consist of at least seven different subtypes and are coupled to intracellular signal transduction via $G$ proteins. However, the lack of specific antagonists for the mGluRs limited the precise characterization of the role of the individual mGluRs. In this study, we investigated the agonist and antagonist activities of a series of phenylglycine derivatives for the mGluRs by examining their effects on the signal transduction of representative mGluR1, mGluR2, and mGluR4 subtypes expressed individually in Chinese hamster ovary cells. The phenylglycine derivatives examined included (S)- and $(R)$ forms of 3-hydroxyphenylglycine (3HPG), 4-carboxy-phenylglycine (4CPG), 4-carboxy-3-hydroxyphenylglycine (4C3HPG), 3-carboxy-4-hydroxyphenylglycine (3C4HPG), and (+)- and (-)- $\alpha$-methyl-4-carboxyphenylglycine ( $\alpha$ M4CPG). Among these 10 compounds, (S)-3HPG acted as an agonist for mGluR1, while (S)-4C3HPG, (S)-3C4HPG, and (S)-4CPG served as effective agonists for mGluR2. The rank order of agonist potencies for MGluR2 was L-glutamate $>$ (S)-4C3HPG $>(S)-3 C 4 H P G>(S)-4 C P G$. No other phenylglycine derivatives showed any definite agonist activity on either mGluR 1 or mGluR2. Among the phenylglycine derivatives with no mGluR1 agonist activity, (S)-4C3HPG, (S)-3C4HPG, (S)-4CPG, and $(+)-\alpha M 4 C P G$ effectively antagonized the action of L-glutamate on mGluR1. The rank order of antagonist potencies was (S)-4C3HPG $\geq(S)-4 C P G \geq(+)-\alpha M 4 C P G>(S)-3 C 4 H P G$. The Schild plot analysis indicated that (RS)-4C3HPG, (S)$4 C P G$, and $(+)-\alpha M 4 C P G$ all act as competitive antagonists for mGluR1 with $\mathrm{pA}_{2}$ values of $4.38,4.46$, and 4.38 , respectively. Furthermore, (+)- $\alpha M 4 C P G$ was an effective competitive antagonist for mGluR2 with a $\mathrm{pA}_{2}$ value of 4.29 . None of the $\mathbf{1 0}$ phenylglycine derivatives showed any agonist or antagonist activity for mGluR4. This investigation demonstrated that (S)-4C3HPG, (S)-4CPG, and (S)-3C4HPG act both as agonists for mGluR2 and as antagonists for mGluR1, and

\footnotetext{
Received July 22, 1993; revised Nov. 10, 1993; accepted Nov. 30, 1993.

This work was supported in part by research grants from the Ministry of Education, Science and Culture of Japan, the Ministry of Health and Welfare of Japan, the UK Medical Research Council, and U.S. Public Health Service NS 26540 .

Correspondence should be addressed to Shigetada Nakanishi, Institute for Immunology, Kyoto University Faculty of Medicine, Yoshida, Sakyo-ku, Kyoto 606, Japan.

Copyright (C) 1994 Society for Neuroscience $0270-6474 / 94 / 143370-08 \$ 05.00 / 0$
}

more importantly, that ( +$)-\alpha M 4 C P G$ serves purely as an antagonist for mGluR1 and mGluR2. The phenylglycine derivatives will be useful for investigating the functions of the mGluR family.

[Key words: phenylglycine derivative, glutamate analog, metabotropic glutamate receptor, agonist potency and selectivity, antagonist potency and selectivity, receptor-expressing cell, signal transduction, Schild plot analysis]

Glutamate receptors play an important role in neuronal plasticity and neurotoxicity in the CNS (Choi and Rothman, 1990; Watkins et al., 1990; Nakanishi, 1992; Bliss and Collingridge, 1993). They are classified into two distinct groups termed ionotropic glutamate receptors and metabotropic glutamate receptors (mGluRs) on the basis of electrophysiological, pharmacological, and molecular studies (Nakanishi, 1992). The ionotropic receptors comprise glutamate-gated, cation-specific channel complexes and are further subdivided into the receptors for NMDA and the non-NMDA receptors for kainate/ $\alpha$-amino-3hydroxy-5-methyl-4-isoxazolepropionate (AMPA) (Nakanishi, 1992; Sommer and Seeburg, 1992). mGluRs are coupled to intracellular second messenger systems via $G$ proteins (Nakanishi, 1992; Schoepp and Conn, 1993). Recent molecular cloning studies have revealed the existence of at least seven different subtypes of mGluRs, termed mGluR 1 to $\mathrm{mGluR} 7$, which share a common structural architecture with a large extracellular domain preceded by the seven membrane-spanning domains (Houamed et al., 1991; Masu et al., 1991; Abe et al., 1992; Nakanishi, 1992; Tanabe et al., 1992; Nakajima et al., 1993; Okamoto et al., 1994). mGluRI and mGluR5 are coupled to the stimulation of the phosphatidylinositol (PI) hydrolysis/ $\mathrm{Ca}^{2+}$ signal transduction, whereas the other five are linked to the inhibition of the cAMP cascade. They also show different agonist selectivities in accordance with their sequence similarities within the mGluR family. mGluR 1 and mGluR5 interact selectively with quisqualate, whereas mGluR2 and mGluR3 potently react with trans-1-aminocyclopcntanc-1,3-dicarboxylate (ACPD) and (2S,1'S,2'S)-2-(carboxycyclopropyl)glycine (Abe et al., 1992; Aramori and Nakanishi, 1992; Hayashi et al., 1992; Tanabe et al., 1992, 1993). mGluR4, mGluR6, and mGluR7 effectively respond to L-2-amino-4-phosphonobutyrate (L-AP4), thus corresponding to the putative L-AP4 receptors characterized in many neuronal cells (Thomsen et al., 1992; Nakajima et al., 1993; Tanabe et al., 1993; Okamolo et al., 1994). The seven mGluR subtypes are thus classified into three subgroups 
on the basis of their sequence similarities, signal transduction mechanisms, and agonist selectivities.

Numerous lines of recent evidence indicate that mGluRs are involved in the regulation of synaptic transmission in the CNS (Schoepp and Conn, 1993). However, the lack of specific antagonists for the mGluRs has limited the precise characterization of the role of the individual mGluRs in glutamate transmission. Recently, a series of phenylglycine derivatives was chemically synthesized, and the effects of these compounds on glutamate transmission in the brain and spinal cord were studied electrophysiologically and biochemically (Watkins et al., 1987; Bashir et al., 1993; Birse et al., 1993; Eaton et al., 1993a,b; Jane et al., 1993). These studies indicated that some of the compounds are effective as agonists or antagonists for mGluRs. The determination of the accurate potencies and subtype specificity of the effective phenylglycine compounds is thus important for the use of these compounds in studies of the functions of the mGluRs. In this investigation, we adopted clonal cell lines expressing a single mGluR subtype and characterized the agonist and antagonist properties of each phenylglycine compound without any ambiguity due to cross-reactivity with different mGluR subtypes. We tested the effects of five pairs of stereoisomers of phenylglycine derivatives on the signal transduction of representative $\mathrm{mGluR} 1, \mathrm{mGluR2}$, and mGluR4 expressed individually in Chinese hamster ovary $(\mathrm{CHO})$ cells. We report here the potencies and subtype specificity of the phenylglycine compounds and indicate that $(+)-\alpha$-methyl-4-carboxyphenylglycine $(\alpha \mathrm{M} 4 \mathrm{CPG})$ acts as a selective antagonist for mGluRl and mGluR2.

\section{Materials and Methods}

Materials. The phenylglycine derivatives used in this study were obtained as follows (for the structures of different phenylglycine derivatives, see Table 1): (RS)-4-carboxyphenylglycine (4CPG), (RS)-4-carboxy-3-hydroxyphenylglycine (4C3HPG), and (RS)- $\alpha \mathrm{M} 4 \mathrm{CPG}$ were synthesized from the correspondingly substituted benzaldehydes (for $4 \mathrm{CPG}$ and $4 \mathrm{C} 3 \mathrm{HPG}$ ) or acetophenone (for $\alpha \mathrm{M} 4 \mathrm{CPG}$ ) by the Strecker reaction (a variation of the method of Steiger, 1955), and the racemates were resolved through their L-lysine salts (Evans et al., 1979); synthesis and resolution of $(R S)$-3-carboxy-4-hydroxyphenylglycine (3C4HPG) were carried out according to the method of Kjær and Larsen (1963); $(R)$ - and (S)-3-hydroxyphenylglycines (3HPG) were prepared from appropriately protected 3-hydroxyphenylacetic acid by enantioselective synthesis, using the method of Evans et al. (1987). Assignment of configuration was by inference from the chiral auxiliaries used in enantioselective synthesis (for 3HPG), sequence of elution in chiral high-performance liquid-chromatography (HPLC) from an asymmetric crown ether column (all except isomers of $\alpha \mathrm{M} 4 \mathrm{CPG}$ ) (Udvarhelyi and Watkins, 1990), and pH-dependent rotational shifts (Greenstein and Winitz, 1961; $\mathrm{Kjær}$ and Larsen, 1963). Since the isomers of $\alpha \mathrm{M} 4 \mathrm{CPG}$ were not separated in chiral HPLC, we did not assign absolute stereochemistry in this case. Based on pH-dependent rotational shifts, however, the (+)and $(-)$-isomers (so termed according to the signs of their rotations as determined in acid solution) are likely to be the $(S)$ - and $(R)$-forms, respectively, as with all the other phenylglycines used in this study. All single enantiomers showed $97 \%$ or greater optical purity (most $>99 \%$ ) in analytical chiral HPLC (Udvarhelyi and Watkins, 1990). Observed specific rotations $\left([\alpha]_{1}^{18}\right.$, , measured in $\left.6 \mathrm{~N} \mathrm{HCl}\right)$ were as follows: $(S)$ $4 \mathrm{CPG},+154^{\circ}(c, 0.25) ;(R)-4 \mathrm{CPG},-160^{\circ}(c, 0.23),(S)-4 \mathrm{C} 3 \mathrm{HPG},+140^{\circ}$ $(c, 0.38) ;(R)-4 \mathrm{C} 3 \mathrm{HPG},-141^{\circ}(c, 0.28),(S)-3 \mathrm{C} 4 \mathrm{HPG},+139^{\circ}(c, 0.8)$; $(R)-3 \mathrm{C} 4 \mathrm{HPG},-141^{\circ}(c, 0.9),(S)-3 \mathrm{HPG},+152^{\circ}(c, 0.12) ;(R)-3 \mathrm{IIPG}$, $-163^{\circ}(c, 0.13),(+)-\alpha \mathrm{M} 4 \mathrm{CPG},+93^{\circ}(c, 052) ;(-)-\alpha \mathrm{M} 4 \mathrm{CPG},-97^{\circ}$ (c, 0.27). The phenylglycine derivatives were dissolved at $50 \mathrm{~mm}$ in an equimolar $\mathrm{NaOH}$ solution and used after $\mathrm{pH}$ adjustment.

Measurements of PI hydrolysis and cyclic AMP formation. Permanent $\mathrm{CHO}$ cell lines expressing individually mGluR1, mGluR2, and mGluR4 were prepared as described previously (Aramori and Nakanishi, 1992; Tanabe et al., 1992, 1993). The agonist and antagonist activities of phenylglycine derivatives for mGluR 1 were determined by measuring total inositol phosphate (IP) formation in mGluR 1-expressing cells as described previously (Aramori and Nakanishi, 1992; Hayashi et al. 1992); mGluR 1-expressing cells were incubated with test reagents for $20 \mathrm{~min}$, and the agonist activity was determined by measuring the formation of a mixture of ${ }^{3} \mathrm{H}$-labeled inositol mono-, bis-, and trisphosphates; for measurements of antagonist activity, mGluR 1-expressing cells were first preincubated with test reagents for $20 \mathrm{~min}$ and then incubated with these reagents for 20 min after the addition of a constant or varying concentration of L-glutamate; the inhibitory effects of the test reagents on the L-glutamate-mediated stimulation of total IP formation were then determined. The agonist and antagonist activities of phenylglycine derivatives for mGluR2 and mGluR4 were determined by measuring changes in levels of the forskolin-induced cyclic AMP formation in mGluR2-expressing and mGluR4-expressing cells, respectively, as described previously (Hayashi et al., 1992; Tanabe et al., 1992, 1993); for measurements of the agonist activity, receptor-expressing cells were incubated with test reagents in the presence of $10 \mu \mathrm{M}$ forskolin for $10 \mathrm{~min}$, and the agonist activity was determined by measuring the inhibition of the forskolin-stimulated cyclic AMP formation; for measurements of the antagonist activity, receptor-expressing cells were first preincubated with test reagents for $20 \mathrm{~min}$ and then further incubated with test reagents for $10 \mathrm{~min}$ after the addition of $10 \mu \mathrm{M}$ forskolin together with a constant or varying concentration of L-glutamate. All experiments for measurements of PI hydrolysis and cyclic AMP formation were carried out at least twice in triplicate.

\section{Results}

Agonist activities of various phenylglycine derivatives for $m G l u R 1, m G l u R 2$, and $m G l u R 4$

The seven mGluR subtypes can be subclassified into three groups on the basis of their sequence similarities, signaling cascades, and agonist selectivities: mGluR 1/mGluR5, mGluR2/mGluR3, and $\mathrm{mGluR} 4 / \mathrm{mGluR} 6 / \mathrm{mGluR} 7$. We chose mGluR1, mGluR2, and mGluR 4 as representatives of each group of the receptors and investigated the effects of 10 phenylglycine derivatives on the signal transduction characteristic of the respective receptor subtypes. We first examined the agonist activities of these phenylglycine derivatives for each of the three mGluR subtypes by the addition of a high concentration ( $1 \mathrm{~mm}$ each) of these compounds to cell lines expressing individual receptor subtypes (Fig. 1). In mGluR 1-expressing cells, L-glutamate ( $1 \mathrm{~mm})$ induced about a 10 -fold increase in total IP formation above control levels (Fig. 1a). Among the 10 phenylglycine derivatives, $(S)$ 3HPG showed a weak agonist activity on mGluR1 (Fig. 1a). No other phenylglycine derivative showed any obvious agonist activity on mGluR 1 at the concentration of $1 \mathrm{~mm}$. We next analyzed the agonist activities of the 10 phenylglycine derivatives in mGluR2-expressing cells. L-Glutamate inhibited the forskolin-induced cAMP accumulation to about $10-20 \%$ of control levels (Fig. $1 b$ ). Four of the phenylglycine derivatives, $(S$ )and $(R)-4 \mathrm{C} 3 \mathrm{HPG},(S)-4 \mathrm{CPG}$, and $(S)-3 \mathrm{C} 4 \mathrm{HPG}$, showed inhibition of the forskolin-stimulated cAMP formation to different extents, but the other six had no such agonist activity in mGluR2expressing cells (Fig. 1b). When the agonist activities of the phenylglycine derivatives were examined in mGluR4-expressing cells, none of them revealed any appreciable inhibitory effcets on the forskolin-stimulated cAMP formation (Fig. 1c). In this experiment, it was confirmed that L-glutamate is effective in reducing the forskolin-stimulated cAMP formation to about $40 \%$ of control levels.

The potencies of the four phenylglycine derivatives effective as mGluR 2 agonists were analyzed in more detail by determining dose-response curves of these compounds as well as $\mathrm{L}$-glutamate for the inhibition of the forskolin-stimulated cAMP formations in mGluR2-expressing cells (Fig. 2). The rank order of 


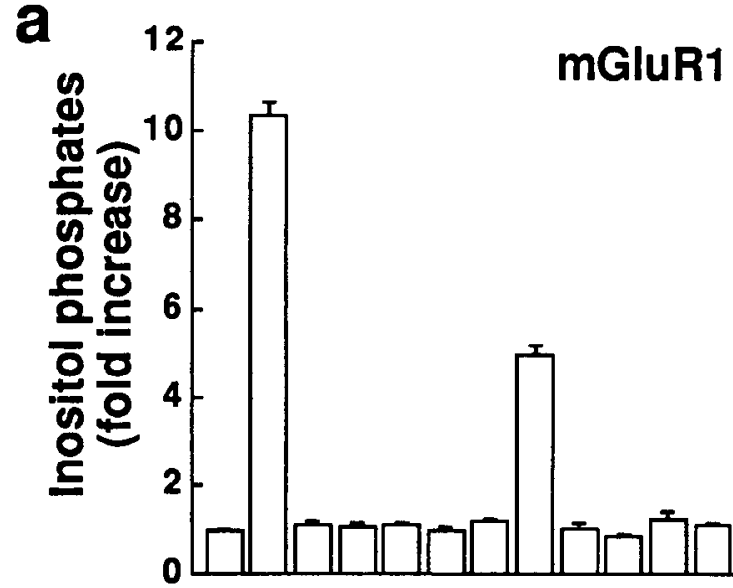

b

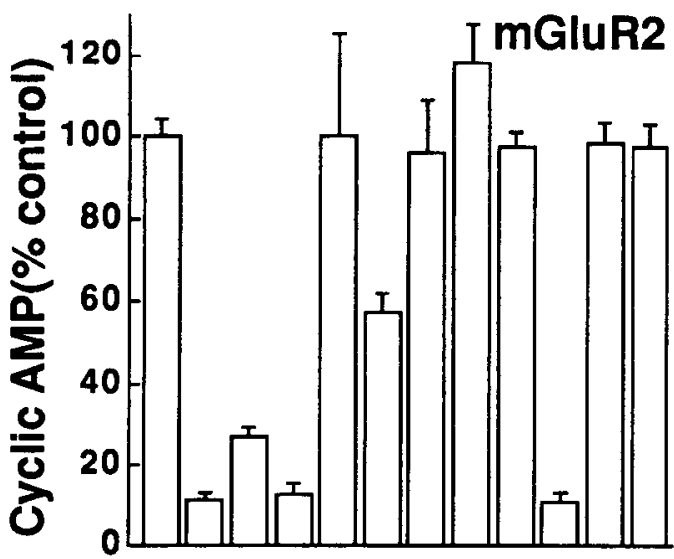

C

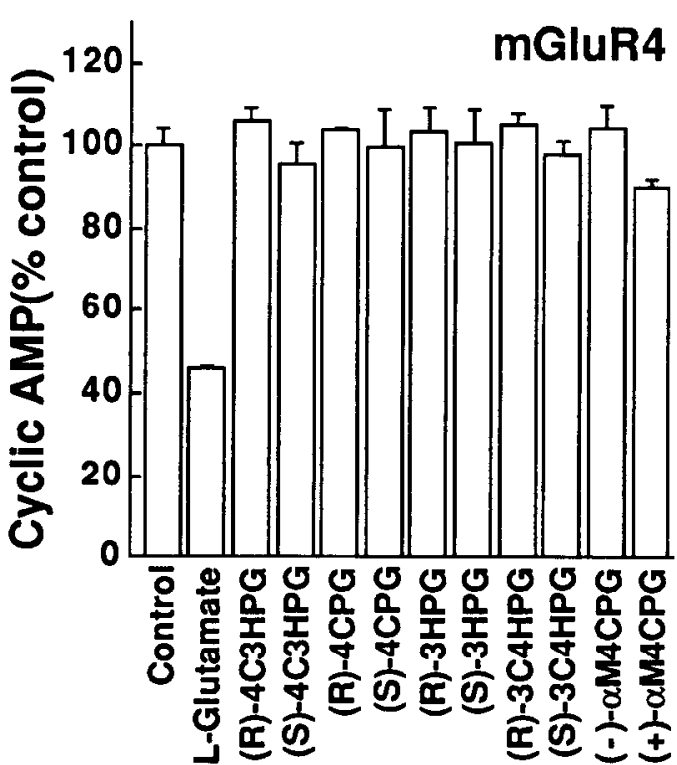

Figure 1. Agonist activities of 10 phenylglycine derivatives for mGluR 1 , mGluR2, and mGluR4. In $a$, mGluR 1-expressing cells were incubated with L-glutamate ( $1 \mathrm{~mm}$ ) or phenylglycine derivatives (1 mM each) for $20 \mathrm{~min}$, and total IP formation was determined. The IP formation is expressed as multiples of IP levels in agonist-untreated cells (Control). Basal levels (Control) of total inositol phosphates were $912 \pm 40 \mathrm{cpm}$. In $b$ and $c$, mGluR2-expressing and mGluR4-expressing cells were incubated with L-glutamate or phenylglycine derivatives ( $1 \mathrm{~mm}$ each) for

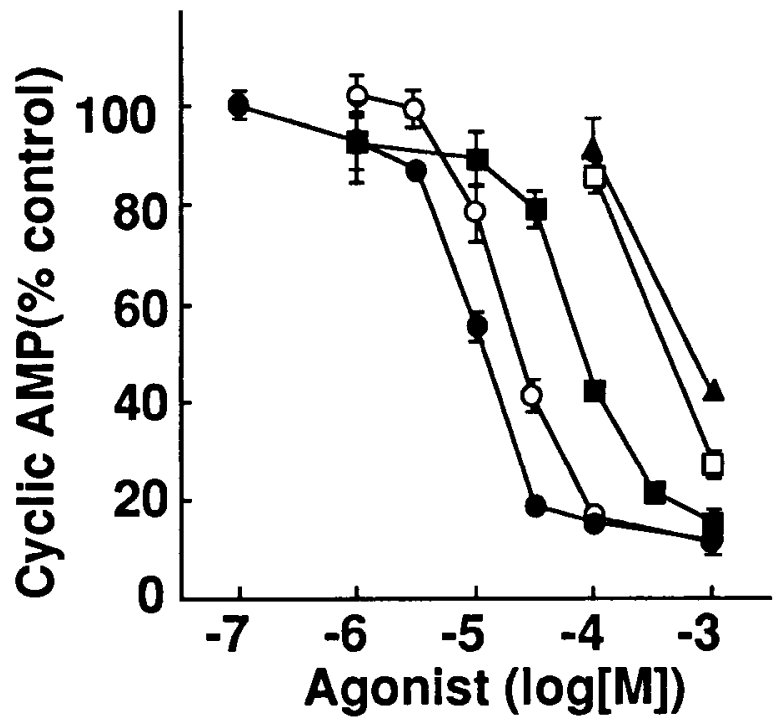

Figure 2. Dose-response curves of phenylglycine derivatives for the inhibition of the forskolin-stimulated cAMP formation in mGluR2expressing cells. mGluR2-expressing cells were incubated with the indicated concentrations of $\mathrm{L}$-glutamate $(\mathbf{O}),(S)-4 \mathrm{C} 3 \mathrm{HPG}(\mathrm{O}),(S)$-3C4HPG $(\square),(R)-4 \mathrm{C} 3 \mathrm{HPG}(\square)$, and $(S)-4 \mathrm{CPG}(\mathbf{\Delta})$. For other details, see Figure 1.

potencies of these compounds was L-glutamate $>(S)-4 \mathrm{C} 3 \mathrm{HPG}$ $>(S)-3 \mathrm{C} 4 \mathrm{HPG}>(R)-4 \mathrm{C} 3 \mathrm{HPG} \geq(S)-4 \mathrm{CPG}$. The half-maximal effective concentrations $\left(\mathrm{EC}_{50}\right)$ of these agonists were $1 \times$ $10^{-5}, 2 \times 10^{-5}, 7 \times 10^{-5}, 3 \times 10^{-4}$, and $5 \times 10^{-4} \mathrm{M}$, respectively.

\section{Antagonist activities of various phenylglycine derivatives for $m G l u R 1, m G l u R 2$, and $m$ GluR4}

The antagonist effects of nine phenylglycine derivatives on mGluR 1 werc detcrmincd by applying $1 \times 10^{-3} \mathrm{M}$ of different phenylglycine compounds to $\mathrm{mGluR} 1$-expressing cells in the presence of $1 \times 10^{-5} \mathrm{M}$ L-glutamate (Fig. $3 a$ ). This concentration of $\mathrm{L}$-glutamate corresponded to the approximate $\mathrm{EC}_{50}$ value of this agonist for mGluR 1 and indeed increased IP levels about four- to fivefold. Among the phenylglycine derivatives applied, $(S)-4 \mathrm{C} 3 \mathrm{HPG},(S)-4 \mathrm{CPG},(S)-3 \mathrm{C} 4 \mathrm{HPG}$, and (+)- $\alpha \mathrm{M} 4 \mathrm{CPG}$ inhibited L-glutamate-induced IP increase in mGluR 1-expressing cells and reduced the IP formation to about control levels (Fig. $3 a$ ). (R)-4C3HPG also partially antagonized the effect of L-glutamate on the mGluR1 activity. Because (S)-3HPG showed an agonist activity, this compound was not included in the above analysis. However, $(S)-3 \mathrm{HPG}$ at the concentrations of $1 \times 10^{-4}$ $\mathbf{M}$ and $1 \times 10^{-3} \mathrm{M}$ exhibited weak inhibitory effects (about $15 \%$ and $25 \%$ inhibition, respectively) on nearly maximally stimulated IP formation evoked by $1 \times 10^{-4} \mathbf{M}$ L-glutamate (data not shown), suggesting that this compound has both agonist and antagonist activities (i.e., partial agonist) on mGluR1. However,

$10 \mathrm{~min}$ in the presence of $10 \mu \mathrm{M}$ forskolin, respectively, and intracellular cAMP levels were determined. cAMP levels in cells treated and untreated with $10 \mu \mathrm{M}$ forskolin were $187.5 \pm 7.7$ and $5.8 \pm 0.5 \mathrm{nmol}$ per well (mGluR2-expressing cells) and $153.1 \pm 2.2$ and $3.7 \pm 0.2 \mathrm{nmol}$ per well (mGluR4-expressing cells), respectively. The cAMP levels in forskolin-stimulated, glutamate-untreated cells (Control) are taken as $100 \%$. The data indicated were taken from representative experiments. The values are means \pm SD (error bars) of triplicate determinations. 


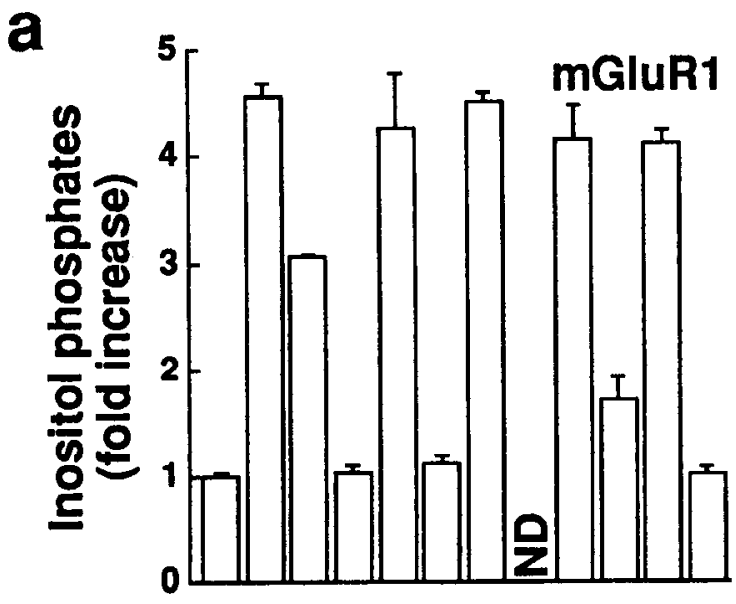

b
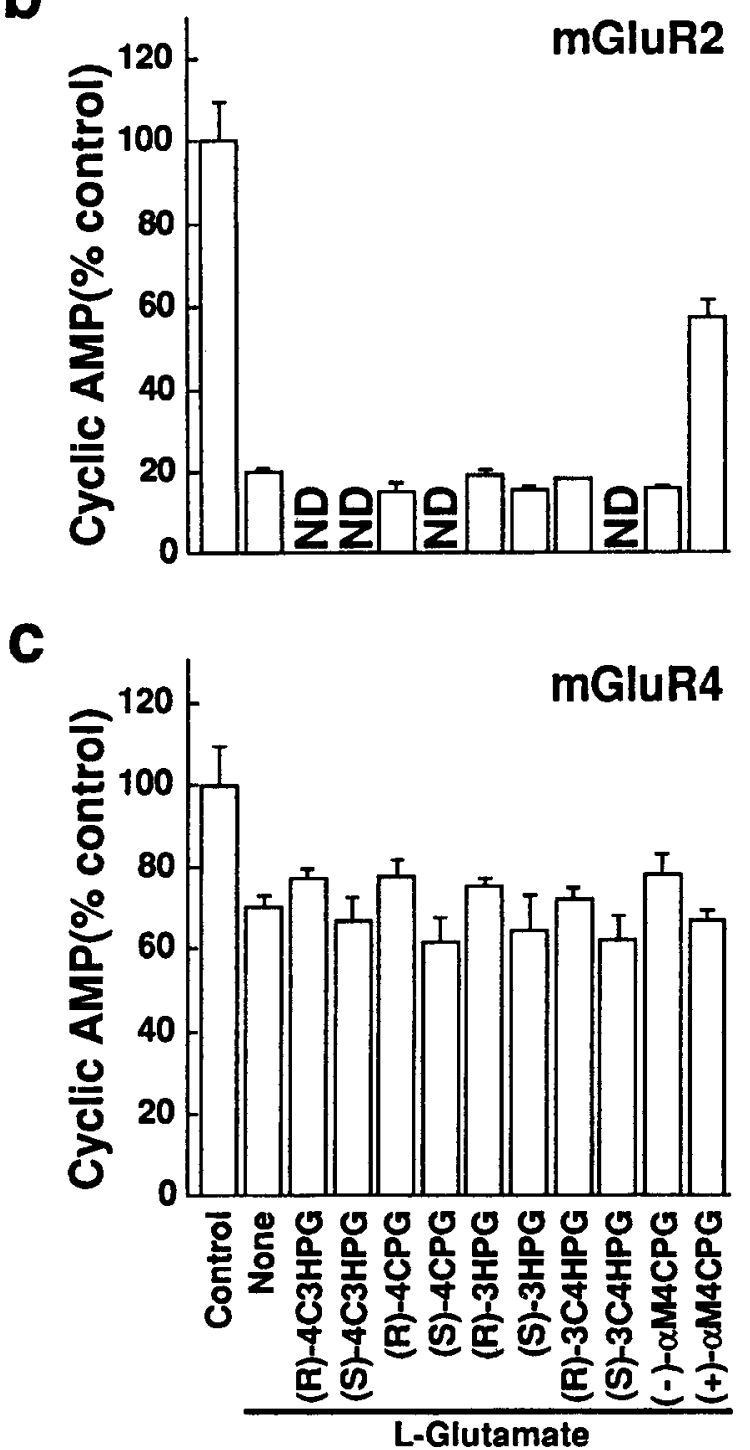

Figure 3. Antagonist activities of phenylglycine derivatives for mGluRl, mGluR2, and mGluR4. In $a$, mGluR l-expressing cells were preincubated with $1 \mathrm{mM}$ phenylglycine derivatives for $20 \mathrm{~min}$ and then incubated with $10 \mu \mathrm{M}$ L-glutamate in the presence of $1 \mathrm{~mm}$ phenylglycine derivatives. Basal levels (Control) of total inositol phosphates were 1106 $\pm 28 \mathrm{cpm}$. In $b$ and $c$, mGluR2-expressing and mGluR4-expressing

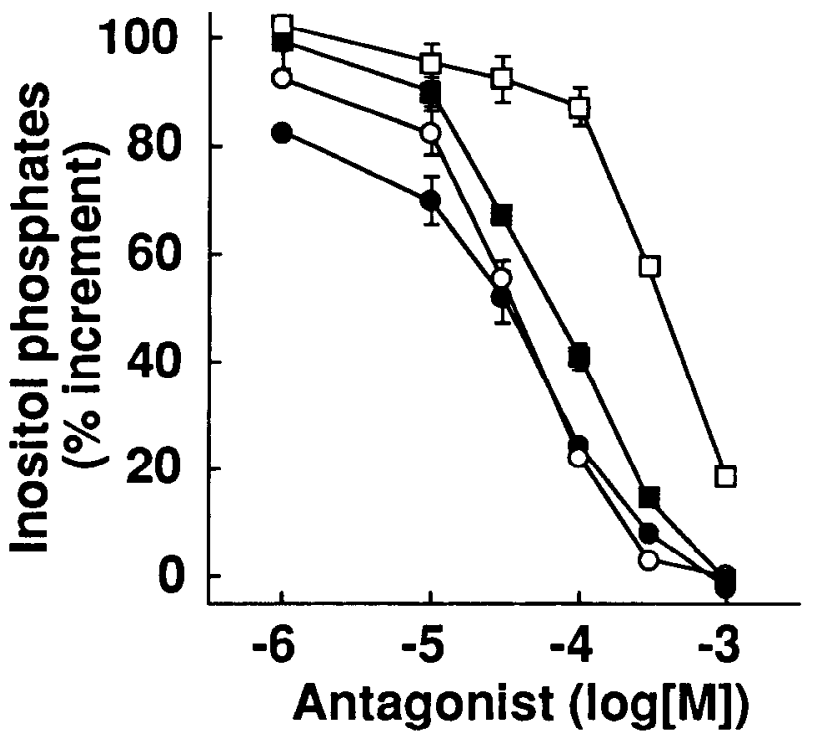

Figure 4. Relative potencies of four phenylglycine derivatives as antagonists for mGluR 1. mGluR l-expressing cells were preincubated with the indicated concentrations of (S)-4C3HPG $(0),(S)-4 C P G(O),(+)$ $\alpha$ M4CPG $(\square)$, and $(S)-3 C 4$ HPG $(\square)$ for $20 \mathrm{~min}$ and further incubated with these compounds for $20 \mathrm{~min}$ in the presence of $10 \mu \mathrm{M} \mathrm{L}$-glutamate. The L-glutamate $(10 \mu \mathrm{M})$-stimulated IP formation in the absence of any antagonist was taken as $100 \%$. The basal level of IP formation was 1617 $\pm 53 \mathrm{cpm}$ and this level increased to $9515 \pm 188 \mathrm{cpm}$ with the addition of $10 \mu \mathrm{M}$ L-glutamate. For other details, see Figure 1.

because both activities were weak, more detailed characterization of $(S)$-3HPG remains to be conducted.

Antagonist activities of six phenylglycine derivatives on mGluR2 were then determined by examining whether the glutamate-mediated inhibition of the forskolin-induced cAMP accumulation was reduced by the addition of $1 \times 10^{-3} \mathrm{M}$ of different phenylglycinc derivatives in mGluR2-cxpressing cells (Fig. $3 b$ ). In this experiment, $3 \times 10^{-5} \mathrm{M} \mathrm{L}$-glutamate was added, and the analysis of $(R)$ - and $(S)-4 \mathrm{C} 3 \mathrm{HPG},(S)-4 \mathrm{CPG}$, and $(S)$ 3C4HPG was omitted, because they showed effective agonist activities on mGluR2. Among the phenylglycine derivatives examined, $(+)-\alpha$ M4CPG partially antagonized the agonist effect of L-glutamate.

The antagonist effects of the 10 phenylglycine derivatives on mGluR4 were then examined by measuring their antagonist actions on L-glutamate-mediated inhibition of the forskolinstimulated cAMP formation in mGluR4-expressing cells (Fig. $3 c$ ). In this experiment, $1 \times 10^{-5} \mathrm{M}$ glutamate was added to activate mGluR4, and the effects of $1 \times 10^{-3} \mathrm{M}$ of different phenylglycine derivatives were analyzed. None of the phenylglycine derivatives showed the antagonist activity on mGluR4. The properties of mGluR 4 are thus clearly different from those of $\mathrm{mGluR} 1$ and $\mathrm{mGluR} 2$, both of which are either activated or

cells were preincubated with $1 \mathrm{~mm}$ phenylglycine derivatives for $20 \mathrm{~min}$ and then incubated with $30 \mu \mathrm{M}$ (for mGluR2) and $10 \mu \mathrm{M}$ (for mGluR4) L-glutamate, together with $10 \mu \mathrm{M}$ forskolin, in the presence of $1 \mathrm{~mm}$ phenylglycine derivatives for $10 \mathrm{~min}$. Intracellular cAMP levels of resultant cells were determined. cAMP levels in cells treated and untreated with $10 \mu \mathrm{M}$ forskolin were $215.5 \pm 20.0$ and $6.2 \pm 0.1 \mathrm{nmol}$ per well (mGluR2-expressing cells) and $147.4 \pm 13.3$ and $4.6 \pm 1.0 \mathrm{nmol}$ per well (mGluR4-expressing cells), respectively. The antagonist activity of some derivatives was not determined (indicated with $N D$ ) because they showed agonist activities. For other details, see Figure 1. 

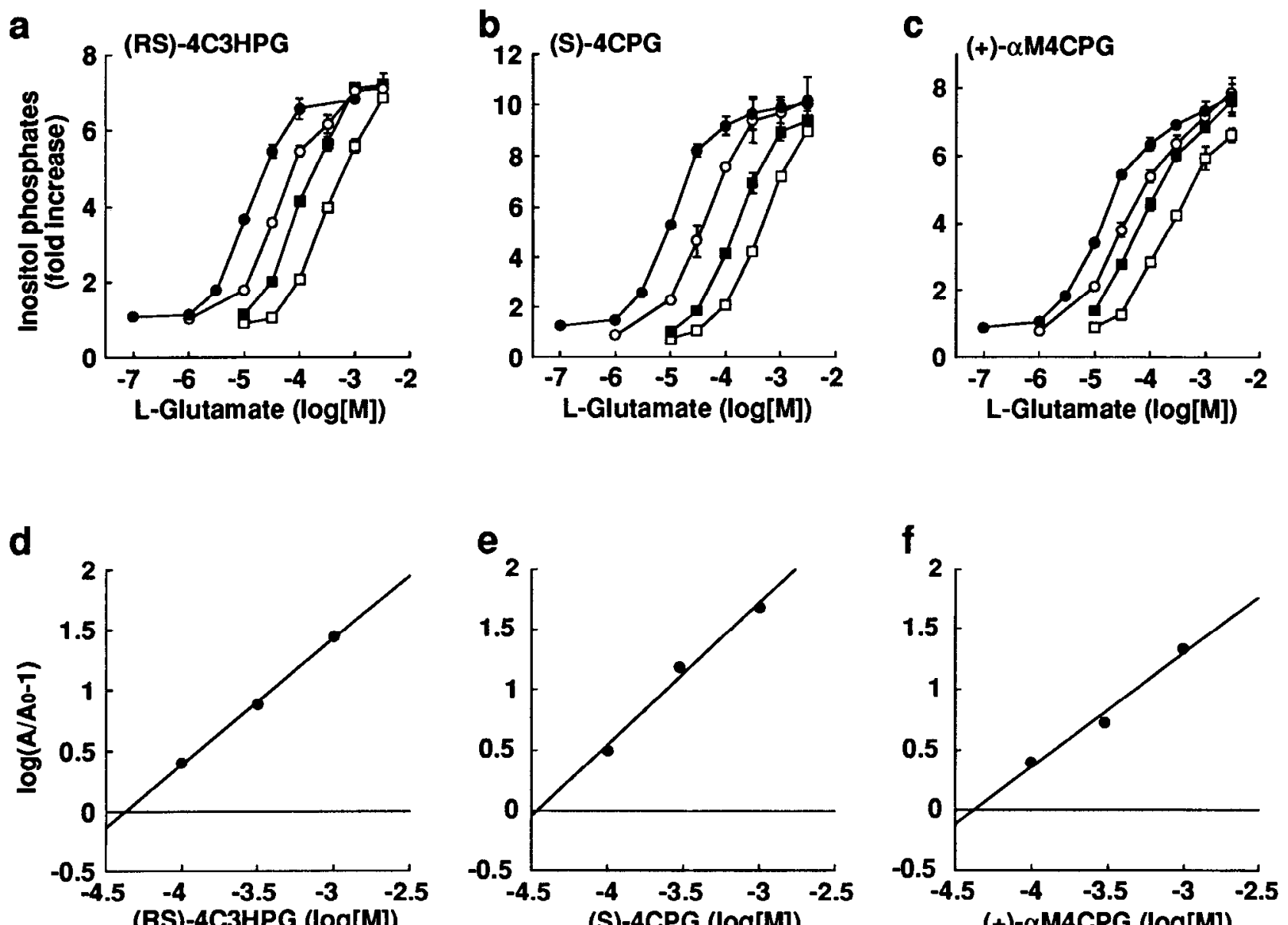

Figure 5. Dose-response curves of L-glutamate for determination of antagonist potencies of three phenylglycine derivatives on mGluR1. IP formation in mGluR 1-expressing cells was determined by the addition of indicated concentrations of L-glutamate alone (๑) or together with 100 $\mu \mathrm{M}(0), 300 \mu \mathrm{M}(0)$, and $1 \mathrm{~mm}(\square)(R S)-4 \mathrm{C} 3 \mathrm{HPG}(a),(S)-4 \mathrm{CPG}(b)$, and (+)- $\alpha \mathrm{M} 4 \mathrm{CPG}(c)$. Schild plots obtained from the EC $\mathrm{E}_{50}$ values estimated from $a-c$ are shown in $d-f$, respectively, where $\mathrm{A} / \mathrm{A}_{0}=\left(\mathrm{EC}_{50}\right.$ for L-glutamate in the presence of phenylglycine derivatives $) /\left(\mathrm{EC}_{50}\right.$ for $\mathrm{L}$-glutamate alone). The $\mathrm{pA}_{2}$ values and slopes were calculated by linear regression analysis.

antagonized, or both, by several different phenylglycine derivatives.

\section{Dose-response analysis of antagonist effects of phenylglycine derivatives on $m G l u R 1$ and $m G l u R 2$}

The antagonist effects of $(S)-4 \mathrm{C} 3 \mathrm{HPG},(S)-4 \mathrm{CPG},(S)-3 \mathrm{C} 4 \mathrm{HPG}$, and $(+)-\alpha \mathrm{M} 4 \mathrm{CPG}$ on $\mathrm{mGluR} 1$ were examined in more detail by determining relative potencies of these compounds in inhibiting the L-glutamate-induced IP formation. We first determined dose-response curves of the antagonist effects of phenylglycine derivative on the IP formation elicited by a constant amount $\left(1 \times 10^{-5} \mathbf{M}\right)$ of L-glutamate (Fig. 4). The result indicated that the rank order of potencies is $(S)-4 C 3 \mathrm{HPG} \geq(S)-4 \mathrm{CPG} \geq(+)$ $\alpha \mathrm{M} 4 \mathrm{CPG}>(S)-3 \mathrm{C} 4 \mathrm{HPG}$. The half-maximal inhibitory concentrations $\left(\mathrm{IC}_{50}\right)$ of the respective compounds were calculated to be $3 \times 10^{-5} \mathrm{M}, 4 \times 10^{-5} \mathrm{M}, 7 \times 10^{-5} \mathrm{M}$, and $4 \times 10^{-4} \mathrm{M}$.

For more quantitative analysis of the antagonist activities of $(R S)-4 \mathrm{C} 3 \mathrm{HPG},(S)-4 \mathrm{CPG}$, and (+)- $\alpha \mathrm{M} 4 \mathrm{CPG}$ for mGluR 1, effects of varying concentrations of these compounds in doseresponse curves of L-glutamate were determined by changing concentrations of both phenylglycine derivatives and L-glutamate in mGluR 1 -expressing cells (Fig. 5). When the concentrations of these phenylglycine derivatives were incrcascd, the doscresponse curves of $\mathrm{L}$-glutamate shifted to the right in parallel, indicating that all these compounds act on mGluR 1 in a competitive manner. The Schild plot analysis of $(R S)-4 C 3 \mathrm{HPG},(S)$ $4 C P G$, and (+)- $\alpha$ M4CPG gave rise to the $\mathrm{pA}_{2}$ values of $4.38(r$ $=0.999 ; r$, correlation coefficient $), 4.46(r=0.993)$, and 4.38 $(r=0.988)$, respectively. The slopes of the Schild plots of the respective compounds were $1.04,1.18$, and 0.94 , confirming that all compounds act as competitive antagonists.

The antagonist effect of $(+)-\alpha \mathrm{M} 4 \mathrm{CPG}$ on mGluR2 was similarly quantitated by changing concentrations of both $(+)$ $\alpha \mathrm{M} 4 \mathrm{CPG}$ and L-glutamate added to MGluR2-expressing cells (Fig. 6). This analysis indicated the dose-response curve of L-glutamate shifts to the right by increasing the concentrations of $(+)-\alpha \mathrm{M} 4 \mathrm{CPG}$. The Schild plot analysis of ( +$)-\alpha \mathrm{M} 4 \mathrm{CPG}$ revealed a $\mathrm{pA}_{2}$ value of $4.29(r=0.993)$ with a slope of 0.891 , suggesting a competitive fashion of antagonism of this compound.

In the above experiments, in contrast to the $(R)$-forms of other phenylglycine derivatives, $(R)-4 C 3 \mathrm{HPG}$ was found to behave as an antagonist for $\mathrm{mGluR} 1$ and an agonist for mGluR2. However, the $(R)-4 C 3 \mathrm{HPG}$ preparation may have contained a trace amount of its enantiomer, and it could not be ascertained whether the observed effects of $(R)-4 C 3 H P G$ reflect its intrinsic activity or arise from the presence of a small amount of $(S)$ 4C3HPG. In subsequent work using chiral HPLC, we have shown 
a

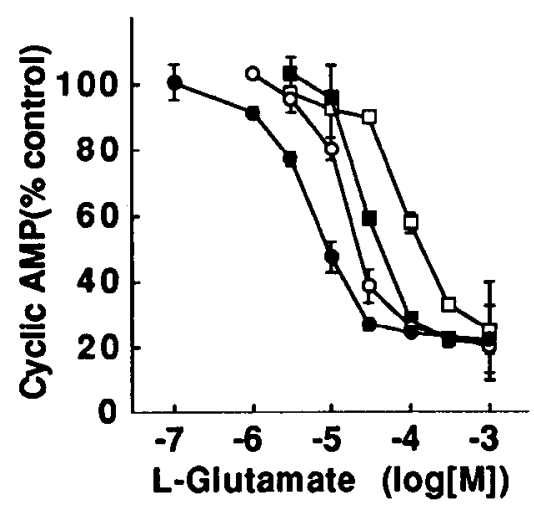

b

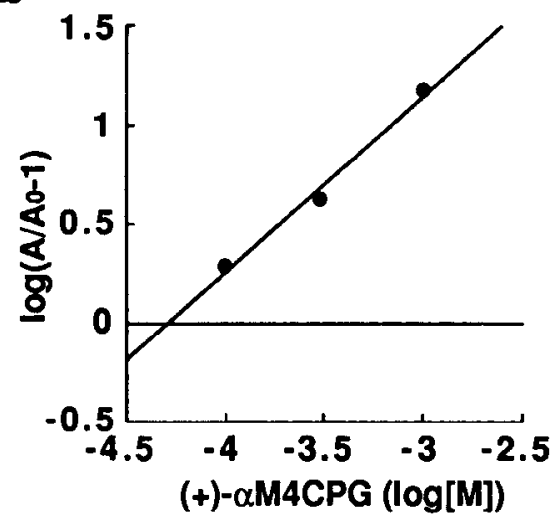

Figure 6. Dose-response curves of L-glutamate for determination of an antagonist potency of $(+)-\alpha \mathrm{M} 4 \mathrm{CPG}$ on mGluR2. Inhibition of forskolin-stimulated cAMP accumulation in mGluR2expressing cells was determined by the addition of the indicated concentrations of L-glutamate alone (O) or together with $100 \mu \mathrm{M}(0), 300 \mu \mathrm{M}(\square)$, and $1 \mathrm{~mm}(\square)(+)-\alpha \mathrm{M} 4 \mathrm{CPG}(a)$. Schild plot obtained from the $\mathrm{EC}_{50}$ values estimated from $a$ is shown in $b$. For other details, see Figures 1 and 5. that with the frequent freezing and thawing of our sample of (R)-4C3HPG over the 1 year period during which this work was conducted, a significant degree of racemization did indeed occur. It is likely, therefore, that the activity reported in this article for $(R)-4 C 3 H P G$ can be ascribed predominantly to contamination with the active $(S)$-isomer.

\section{Discussion}

In order to investigate the function of specific receptors in the CNS using new pharmacological tools, it is first necessary to establish the specificity of the new agonists and/or antagonists for those receptors. In the present case, the recent development of a series of phenylglycine derivatives for the investigation of mGluR function required initially that the selectivity of the new agents for metabotropic versus ionotropic glutamate receptors be established. A series of electrophysiological experiments on neonatal rat motoneurons in vitro and rat thalamic neurons in vivo showed that while the $(R)$-forms of some of these phenylglycines (4CPG, 4C3HPG, 3C4HPG) have significant antagonist activity at NMDA (especially) and AMPA/kainate receptors, the (S)-forms of the same and other phenylglycines, including $3 \mathrm{HPG}$ and $\alpha \mathrm{M} 4 \mathrm{CPG}$, have little or no such antagonist activity and could even potentiate NMDA- or AMPA-induced responses (Birse et al., 1993; Jane et al., 1993; Jones et al., 1993). The results obtained with the $(S)$-phenylglycine derivatives were consistent with the conclusion that the main effects of these compounds were mediated selectively by mGluRs (Pook et al., 1992; Birse et al., 1993; Eaton et al., 1993b; Glaum et al., 1993; Jane et al., 1993; Jones et al., 1993; Kemp et al., 1994). However, it was important to establish the activity of both forms of all of the substances at particular mGluR subtypes.

In this investigation, we determined the potencies and subtype specificity of the agonist and antagonist activities of phenylglycine derivatives by adopting clonal cell lines expressing a dif-

Table 1. Summary of $\mathrm{EC}_{50}$ and $\mathrm{IC}_{50}$ values of the agonist and antagonist activities of phenylglycine derivatives on representative mGluR1, mGluR2, and mGluR4 expressed individually in CHO cells

\begin{tabular}{|c|c|c|c|c|c|c|c|c|c|c|}
\hline & \multirow{2}{*}{\multicolumn{3}{|c|}{ Chemical structure" }} & & \multirow{2}{*}{\multicolumn{2}{|c|}{ mGluR 1}} & \multirow{2}{*}{\multicolumn{2}{|c|}{ mGluR2 }} & \multicolumn{2}{|l|}{ mGluR4 } \\
\hline & & & & & & & & & \multirow[b]{2}{*}{ Agonist } & \multirow{2}{*}{$\begin{array}{l}\text { Antag- } \\
\text { onist }\end{array}$} \\
\hline & $\mathbf{R}_{1}$ & $\mathrm{R}_{2}$ & $\mathbf{R}_{3}$ & & Agonist & Antagonist & Agonist & Antagonist & & \\
\hline \multirow[t]{2}{*}{$4 \mathrm{C} 3 \mathrm{HPG}$} & $-\mathrm{COOH}$ & $-\mathrm{OH}$ & $-\mathrm{H}$ & $(S)$ & $-"$ & $\begin{array}{l}3 \times 10^{-5} \mathrm{M} \\
\mathrm{pA}_{2}=4.38^{d}\end{array}$ & $2 \times 10^{-5} \mathrm{M}$ & ND & - & - \\
\hline & & & & $(R)$ & - & $>10^{-3} \mathbf{M}$ & $3 \times 10^{-4} \mathbf{M}$ & ND & - & - \\
\hline \multirow[t]{2}{*}{$4 \mathrm{CPG}$} & $-\mathrm{COOH}$ & $-\mathrm{H}$ & $-\mathrm{H}$ & $(S)$ & - & $\begin{array}{l}4 \times 10^{-5} \mathrm{M} \\
\mathrm{pA}_{2}=4.46\end{array}$ & $5 \times 10^{-4} \mathrm{M}$ & ND & - & - \\
\hline & & & & $(R)$ & - & - & - & - & - & - \\
\hline \multirow[t]{2}{*}{$3 \mathrm{HPG}$} & $-\mathrm{H}$ & $-\mathrm{OH}$ & $-\mathrm{H}$ & $(S)$ & $1 \times 10^{-3} \mathrm{M}$ & ND & - & - & - & - \\
\hline & & & & $(R)$ & - & - & - & - & - & - \\
\hline \multirow[t]{2}{*}{$3 \mathrm{C} 4 \mathrm{HPG}$} & $-\mathrm{OH}$ & $-\mathrm{COOH}$ & $-\mathrm{H}$ & $(S)$ & - & $4 \times 10^{-4} \mathrm{M}$ & $7 \times 10^{-5} \mathbf{M}$ & ND & - & - \\
\hline & & & & $(R)$ & - & - & - & - & - & - \\
\hline \multirow[t]{2}{*}{$\alpha \mathrm{M} 4 \mathrm{CPG}$} & $-\mathrm{COOH}$ & $-\mathrm{H}$ & $-\mathrm{CH}_{3}$ & $(+)$ & - & $\begin{array}{l}7 \times 10^{-5} \mathrm{M} \\
\mathrm{pA}_{2}=4.38\end{array}$ & - & $\mathrm{pA}_{2}=4.29$ & - & - \\
\hline & & & & $(-)$ & - & - & - & - & - & - \\
\hline
\end{tabular}

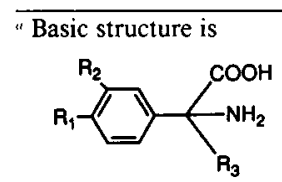

"No activity.

' Not determined.

"This pA, value was determined for a mixture of $(R)$ - and $(S)$-forms of 4 C3HPG. 
ferent mGluR subtype. The data obtained in this investigation are summarized in Table 1 . The results indicate that the phenylglycine derivatives possess different agonist and antagonist activities, dependent on the species and positions of side chains incorporated into the phenylglycine core structure. The absolute stereochemistry of $\alpha \mathrm{M} 4 \mathrm{CPG}$ used remains undetermined, but the $(+)$ - and $(-)$-isomers of this compound are likely to correspond to the $(S)$ - and $(R)$-forms, respectively. This study thus indicates that both the agonist and antagonist effects of phenylglycine derivatives on $m$ GluRs are exerted in a stereoselective manner in that the $(S)$-forms are effective, but the $(R)$-forms have no or little activity. More importantly, our results disclose that the antagonists of phenylglycine derivatives act in a competitive manner. Although most of these compounds also show agonist effects on a different mGluR subtype, $(+)-\alpha M 4 C P G$ is a pure antagonist for both mGluR 1 and mGluR2. The previous studies indicated that DL-2-amino-3-phosphonopropionate (DLAP3) is capable of antagonizing some effects of mGluRs in neuronal preparations (Schoepp and Johnson, 1989; Birse et al., 1993). DL-AP3, however, behaves as an uncompetitive antagonist for ACPD-induced PI hydrolysis in rat hippocampal slices (Schoepp et al., 1990) and rat cerebral cortical slices (Birse et al., 1993). Moreover, this compound failed to antagonize the action of the cloned mGluR1, mGluR2, or mGluR4 expressed in CHO cells (Aramori and Nakanishi, 1992; Y. Hayashi and S. Nakanishi, unpublished observations). Thus, the phenylglycine derivatives and DL-AP3 are different in their modes of inhibitory action on mGluRs. Furthermore, (+)- $\alpha$ M4CPG exhibits little effect on either the NMDA receptor or the AMPA/ kainate receptor (Jane et al., 1993) and thus represents the first selective antagonist for the mGluR family.

With some exceptions, discussed below, the above characterization of phenylglycine derivatives is consistent with the reports of these compounds studied in neuronal cell and slice preparations. In neonatal rat cerebral cortex slices, $(S)-3 \mathrm{HPG}$ moderately stimulates PI hydrolysis, whereas $(S)-4 C P G$ and $(R S)-\alpha \mathrm{M} 4 \mathrm{CPG}$ antagonize ACPD-stimulated PI hydrolysis in a competitive manner (Birse et al., 1993; Faton et al., 1993h). Furthermore, $(S)-4 C P G,(S)-4 C 3 \mathrm{HPG}$, and $(R S)-\alpha \mathrm{M} 4 \mathrm{CPG}$ all antagonize ACPD-induced depolarization in neonatal rat motoneurons and ACPD-induced excitation in rat thalamic neurons (Birse et al., 1993; Eaton et al., 1993a,b; Jane et al., 1993). These findings agree well with the actions of these compounds on the PI-coupled mGluR1 subgroup found in the present work. However, some apparent inconsistencies do present themselves. Thus, (S)-4C3HPG was not found to antagonize PI hydrolysis in rat cerebral cortex slices but instead appeared to be a weak agonist (Birse et al., 1993). This response pattern of (S)-4C3HPG is apparently different from that observed for mGluR 1 in this investigation, but the reason for this discrepancy remains to be determined. A more important inconsistency concerns the reported action of $(+)-\alpha M 4 C P G$ as an antagonist of ACPD-induced and L-AP4-induced depressant effects on monosynaptic excitation in neonatal rat motoneurons (Pook et al., 1993; Kemp et al., 1994). Such ACPD and L-AP4 effects (Evans et al., 1982; Cotman et al., 1986; Pook et al., 1992) are considered likely to be mediated by presynaptic mGluRs negatively coupled to the cAMP cascade (Tanabe et al., 1992, 1993; Thomsen et al., 1992; Okamoto et al., 1994). In conformity with this hypothesis, (+)$\alpha \mathrm{M} 4 \mathrm{CPG}$ antagonizes both the ACPD-mediated and L-AP4mediated inhibition of forskolin-stimulated cAMP formation in guinea pig cerebral cortical slices (Kemp et al., 1994). While the inhibitory effects of $(+)-\alpha \mathrm{M} 4 \mathrm{CPG}$ on the ACPD-mediated responses are consistent with the antagonist actions of this compound on the mGluR2 subgroup found in the present work, the action of ( +$)-\alpha$ M4CPG on the L-AP4 responses cannot be explained by the properties of the L-AP4-sensitive mGluR4 reported here. The explanation of this inconsistency is currently unclear and may suggest that a different L-AP4-sensitive mGluR subtype is responsible for inducing L-AP4 responses in neonatal motoneurons and the cerebral cortex.

Recently, Bashir et al. (1993) indicated that (RS)- $\alpha \mathrm{M} 4 \mathrm{CPG}$ inhibits the ACPD-induced intracellular $\mathrm{Ca}^{2+}$ mobilization in $\mathrm{CHO}$ cells expressing the cloned $\mathrm{mGluR} 1$. They then used $(R S)$ $\alpha \mathrm{M} 4 \mathrm{CPG}$ to examine the involvement of mGluRs in long-term potentiation and indicated that synaptic activation of mGluRs is necessary for the induction of both NMDA receptor-dependent and -independent forms of long-term potentiation in the hippocampus (Bashir et al., 1993). Although the mGluR subtype involved in long-term potentiation remained to be determined, it is already clear that the phenylglycine derivative is very useful as a tool to investigate the role of mGluRs in the integrative brain functions.

The phenylglycine derivatives share the fundamental structure with L-glutamate in that they have an $\alpha$-amino acid moiety and an $\omega$-anionic group. The characteristic feature of phenylglycine derivatives is the presence of a benzene ring within this structure. This benzene ring directs the $\omega$-anionic group into a particular steric arrangement with respect to the $\alpha$-carbon moiety (Watkins et al., 1990). The conformational restriction of the glutamate chain has been shown to be very important in providing the specificity of agonists or antagonists not only among the different families of glutamate receptors but also within the members of the mGluR family (Shinozaki et al., 1989; Watkins et al., 1990; Hayashi et al., 1992). Another characteristic feature of phenylglycine derivatives is the possession of $\pi$ electrons conferred by the benzene ring. These electrons may also contribute to the interaction of the phenylglycine derivatives with particular amino acids in the receptor molecules.

Several properties characteristic of different phenylglycine derivatives may also be discussed on the basis of the comparison of different side chains attached to the phenylglycine core structure. $(S)-4 C 3 H P G,(S)-4 C P G$, and $(S)-3 C 4 H P G$ all show agonist activities on mGluR 2 and antagonist activities on mGluR 1 . The potency difference in both mGluR2 agonist and mGluR 1 antagonist activities observed between $(S)-4 C 3 \mathrm{HPG}$ and $(S)$ $3 \mathrm{C} 4 \mathrm{HPG}$ indicates the importance of the relative positions of the carboxyl group and the hydroxyl group attached to the benzene ring. In contrast, $(S)-4 \mathrm{C} 3 \mathrm{HPG}$ and $(S)-4 \mathrm{CPG}$ show an equivalent antagonist potency for $\operatorname{mGluR} 1$, but the former is more potent than the latter in the agonist activity for mGluR2. This finding suggests that the presence of a hydroxyl group as a second anionic group may facilitate the interaction of $(S)$ 4C3IIPG with the mGluR2 molecule. More interestingly, the agonist activity for mGluR2 is converted into an antagonist activity for the same receptor subtype by the addition of a methyl group on the $\alpha$-carbon of (S)-4CPG [namely, (+)- $\alpha \mathrm{M} 4 \mathrm{CPG}$ ]. This methyl group must play a role in preventing activation of the receptor while still allowing binding of the molecule competitively with L-glutamate. Further modification of the phenylglycine would be interesting not only for the understanding of the structure-activity relationship of the mGluR ligands but also for development of new agonists and antagonists for this receptor family. 


\section{References}

Abe $\Upsilon$, Sugihara $H$, Nawa $H$, Shigemoto R, Mizuno N, Nakanishi S (1992) Molecular characterization of a novel metabotropic glutamate receptor mGluR5 coupled to inositol phosphate/ $\mathrm{Ca}^{2+}$ signal transduction. J Biol Chem 267:13361-13368.

Aramori I, Nakanishi S (1992) Signal transduction and pharmacological characteristics of a metabotropic glutamate receptor, mGluR1, in transfected $\mathrm{CHO}$ cells. Neuron 8:757-765.

Bashir ZI, Bortolotto ZA, Davies CH, Berretta N, Irving AJ, Seal AJ, Henley JM, Jane DE, Watkins JC, Collingridge GL (1993) Induction of LTP in the hippocampus needs synaptic activation of glutamate metabotropic receptors. Nature 363:347-350.

Birse EF, Eaton SA, Jane DE, Jones PLStJ, Porter RHP, Pook PC-K, Sunter DC, Udvarhelyi PM, Wharton B, Roberts PJ, Salt TE, Watkins JC (1993) Phenylglycine derivatives as new pharmacological tools for investigating the role of metabotropic glutamate receptors in the central nervous system. Neuroscience 52:481-488.

Bliss TVP, Collingridge GL (1993) A synaptic model of memory: longterm potentiation in the hippocampus. Nature 361:31-39.

Choi DW, Rothman SM (1990) The role of glutamate neurotoxicity in hypoxic-ischemic neuronal death. Annu Rev Neurosci 13:171182.

Cotman CW, Flatman JA, Ganong AH, Perkins MN (1986) Effects of excitatory amino acid antagonists on evoked and spontaneous excitatory potentials in guinea-pig hippocampus. J Physiol (Lond) 378:403-415.

Eaton SA, Birse EF, Wharton B, Sunter DC, Udvarhelyi PM, Watkins JC, Salt TE (1993a) Mediation of thalamic sensory responses in vivo by ACPD-activated excitatory amino acid receptors. Eur J Neurosci $5: 186-189$.

Eaton SA, Jane DE, Jones PLStJ, Porter RHP, Pook PC-K, Sunter DC, Udvarhelyi PM, Roberts PJ, Salt TE, Watkins JC (1993b) Competitive antagonism at metabotropic glutamate receptors by $(S)$-4carboxyphenylglycine and $(R S)-\alpha$-methyl-4-carboxyphenylglycine. Eur J Pharmacol [Mol Pharmacol] 244:195-197.

Evans RH, Francis AA, Hunt K, Oakes DJ, Watkins JC (1979) Anlagunisill of excitatory amino acid-induced responses and of synaptic excitation in the isolated spinal cord of the frog. Br J Pharmacol 67: 591-603.

Evans RH, Francis AA, Jones AW, Smith DAS, Watkins JC (1982) The effects of a series of $\omega$-phosphonic $\alpha$-carboxylic amino acids on electrically evoked and excitant amino acid-induced responses in isolated spinal cord preparations. $\mathrm{Br} \mathrm{J}$ Pharmacol 75:65-75.

Evans DA, Ellman JA, Dorow RL (1987) Asymmetric halogenation of chiral imide enolates. A general approach to the synthesis of enantiomerically pure $\alpha$-amino acids. Tetrahedron Lett 28:1123-1126.

Glaum SR, Sunter DC, Udvarhelyi PM, Watkins JC, Miller RJ (1993) The actions of phenylglycine derived metabotropic glutamate receptor antagonists on multiple $(1 S, 3 R)-\mathrm{ACPD}$ responses in the rat nucleus of the tractus solitarius. Neuropharmacology 32:1419-1425.

Greenstein JP, Winitz M (1961) Chcmistry of the amino acids, Vol 1, pp 83-85. New York: Wiley.

Hayashi Y, Tanabe Y, Aramori I, Masu M, Shimamoto K, Ohfune Y, Nakanishi S (1992) Agonist analysis of 2-(carboxycyclopropyl)glycine isomers for cloned metabotropic glutamate receptor subtypes expressed in Chinese hamster ovary cells. Br J Pharmacol 107:539-543.

Houamed KM, Kuijper JL, Gilbert TL, Haldeman BA, O'Hara PJ, Mulvihill ER, Almers W, Hagen FS (1991) Cloning, expression, and gene structure of a $G$ protein-coupled glutamate receptor from rat brain. Science 252:1318-1321.

Jane DE, Jones PLStJ, Pook PC-K, Salt TE, Sunter DC, Watkins JC (1993) Stereospecific antagonism by (+)- $\alpha$-methyl-4-carboxyphenylglycine (MCPG) of ( $1 S, 3 R)$-ACPD-induced effects in neonatal rat motoneurones and rat thalamic neurones. Neuropharmacology 32 : $725-727$.

Jones PLStJ, Birse EF, Jane DE, Jones AW, Mewett KN, Pook PC-K, Sunter DC, Udvarhelyi PM, Wharton B, Watkins JC (1993) Agonist and antagonist actions of phenylglycine derivatives at depolarizationmediating $(1 S, 3 R)$-ACPD receptors in neonatal rat motoneurones. Br J Pharmacol 108:86p.
Kemp M, Roberts P, Pook P, Jane D, Jones A, Jones P, Sunter D, Udvarhelyi P, Watkins J (1994) Antagonism of presynaptically mediated depressant responses and cyclic AMP-coupled metabotropic glutamate receptors. Eur J Pharmacol [Mol Pharmacol] 266:187-192.

Kjær A, Larsen PO (1963) D-(3-Carboxy-4-hydroxyphenyl)-glycine and related amino acids in higher plants. Acta Chem Scand 17:23972409.

Masu M, Tanabe Y, Tsuchida K, Shigemoto R, Nakanishi S (1991) Sequence and expression of a metabotropic glutamate receptor. Nature 349:760-765.

Nakajima $Y$, Iwakabe $H$, Akazawa $C$, Nawa $H$, Shigemoto R, Mizuno $N$, Nakanishi S (1993) Molecular characterization of a novel retinal metabotropic glutamate receptor mGluR6 with a high agonist selectivity for L-2-amino-4-phosphonobutyrate. J Biol Chem 268:1186811873.

Nakanishi S (1992) Molecular diversity of glutamate receptors and implications for brain function. Science 258:597-603.

Okamoto N, Hori S, Akazawa C, Hayashi Y, Shigemoto R, Mizuno N, Nakanishi S (1994) Molecular characterization of a new metabotropic glutamate receptor mGluR7 coupled to inhibitory cyclic AMP signal transduction. J Biol Chem 269:1231-1236.

Pook PC-K, Sunter DC, Udvarhelyi PM, Watkins JC (1992) Evidence for presynaptic depression of monosynapti ixcitation in neonatal rat motoneurones by $(1 S, 3 S)$ - and $(1 S, 3 R)$-ACPD. Exp Physiol 77:529532.

Pook PC-K, Birse EF, Jane DE, Jones AW, Jones PLStJ, Mewett KN, Sunter DC, Udvarhelyi PM, Wharton B, Watkins JC (1993) Differential actions of the metabotropic glutamate receptor antagonists $4 \mathrm{C}$-PG and $\alpha \mathrm{M} 4 \mathrm{C}$-PG at I-AP4-like receptors in neonatal rat spinal cord. Br J Pharmacol 108:87P.

Schoepp DD, Conn PJ (1993) Metabotropic glutamate receptors in brain function and pathology. Trends Pharmacol Sci 14:13-20.

Schoepp DD, Johnson BG (1989) Inhibition of excitatory amino acidstimulated phosphoinositide hydrolysis in the neonatal rat hippocampus by 2-amino-3-phosphonopropionate. J Neurochem 53:1865-1870.

Schoepp DD, Johnson BG, Smith ECR, McQuaid LA (1990) Stereoselectivity and mode of inhibition of phosphoinositide-coupled excitatory amino acid receptors by 2-amino-3-phosphonopropionic acid Mol Pharmacol 38:222-228.

Shinozaki H, Ishida M, Shimamoto K, Ohfune $Y$ (1989) Potent NMDAlike actions and potentiation of glutamate responses by conformational variants of a glutamate analogue in the rat spinal cord. $\mathrm{Br} \mathrm{J}$ Pharmacol 98:1213-1224.

Sommer B, Seeburg PH (1992) Glutamate receptor channels: novel properties and new clones. Trends Pharmacol Sci 13:291-296.

Steiger RE (1955) $\alpha$-Aminodiethylacetic acid. In: Organic syntheses coll, Vol 3 (Horning EC, ed), pp 66-69. New York: Wiley.

Tanabe Y, Masu M, Ishii T, Shigemoto R, Nakanishi S (1992) A family of metabotropic glutamate receptors. Neuron 8:169-179.

Tanabe Y, Nomura A, Masu M, Shigemoto R, Mizuno N, Nakanishi $S$ (1993) Signal transduction, pharmacological properties, and expression patterns of two rat metabotropic glutamate receptors, mGluR3 and mGluR4. J Neurosci 13:1372-1378.

Thomsen C, Kristensen P, Mulvihill E, Haldeman B, Suzdak PD (1992) L-2-Amino-4-phosphonobutyrate (L-AP4) is an agonist at the type IV metabotropic glutamate receptor which is negatively coupled to adenylate cyclase. Eur J Pharmacol [Mol Pharmacol] 227:361-362.

Udvarhelyi PM, Watkins JC (1990) Direct resolution of some phenylglycines by liquid chromatography on a chiral crown ether phase. Chirality 2:200-204.

Watkins JC, Evans RH, Mewett KN, Olverman HJ, Pook PC (1987) Recent advances in the pharmacology of excitatory amino acids. In: Neurology and neurobiology, Vol 24, Excitatory amino acid transmission (Hicks TP, Lodge D, McLennan H, eds), pp 19-26. New York: Liss.

Watkins JC, Krogsgaard-Larsen P, Honoré T (1990) Structure-activity relationships in the development of excitatory amino acid receptor agonists and competitive antagonists. Trends Pharmacol Sci 11:2533. 